\title{
Editorial
}

\section{Golden age of Tonsillectomy}

Hippocrates (5th Century BC) defined tonsils as "antiades" on account of the symmetrical oro-pharyngeal site and had already described this pathological condition, but had limited surgical treatment only to incision of abscesses $^{1}$. The tonsils are lymphoid organs strategically located at the entrance of the digestive and respiratory systems. The surgical removal of the tonsils has been practised as long as three thousand years, as citated in Hindu literature. The Roman doctor Cornelius Celsus, in the first century before Christ, was the first one to describe a tonsillectomy, doing the surgical procedure with his own finger for dissection and removal of the structures ${ }^{1}$. Versalius in 1543 was the first one to describe the tonsils in details, including its sanguine irrigation. Duverney, in 1761 , made the first accurate description of the pharyngeal region, but detailed anatomical and histologic studies only had been realized in the 19th century by Wilhelm Von Waldeyer. Physick in 1828 introduced instruments for the fast accomplishment of the tonsillectomy. In Brazil, the first surgery was realized in the decade of 1920 by a surgeon in the Santa Casa of Sao Paulo, Schmidt Sarmento. Currently the tonsillectomy is the most realized surgical procedure in children in the world $^{2}$.

Cornélio Celsus, in the 1st century B.C., was the first to describe tonsillectomy surgery. He reported the procedure performance for dissection and removal of the structures. Celsus applied a mixture of vinegar and milk in the surgical specimen to hemostasis and also described his difficulty in doing that due to lack of proper anesthesia ${ }^{2,3}$. Tonsillectomy, therefore, was the last way of therapy in that time. Aetius de Amida recommended ointment, oils and corrosive formulas with frog fat to treat infections. Some recommendations for removing tonsils in that time included night enuresis (bed-wetting), convulsions, laryngeal stridor, hoarseness, chronic bronchitis ${ }^{2}$. Other techniques for removing tonsils arouse in the middle Ages, such as the ones using cotton lines to connect the base. The lines were daily tighted and then tonsils fell ${ }^{2}$. The removal procedure of tonsils was abandoned up to 16th century when tools were adjusted to perform tonsillectomy. Paré, in 1564, and Scultetus, in 1655 , created equipment that allowed placing an oval shape instrument around the uvula, which cut it off by strangulation. Hildanus, in 1646, and Heister in 1763, presented devices similar to a guillotine-cutter for uvulotomy. These instruments were modified by Physick, who, in 1828, in the United States, created the tonsilotome, used successfully in tonsillectomies ${ }^{2,3}$.

However, even with the exaltation of Physick, it seems to be of the French surgeon Pierre Desault the priority of the use of an instrument to perform tonsillectomy accomplishment. Desault used, in 1770, a metallic device developed to break up bladder stones. This half-moon shape like instrument had, in its extremity, a small knife that suited perfectly to tonsils. As he did not make a formal communication when using such device, Desault was left apart ${ }^{4}$. 
New instruments were created using as archetype Physick's tonsilotome model. Fahnestock, in the United States, 1832, Mackenzie in London, 1880, Brunings in 1908 and Sluder in 1911 in the United States developed similar equipment. Greenfield Sluder, an ENT doctor, in Saint Louis was not the first to use the guillotine-cutter for tonsillectomy ${ }^{4}$.

Tonsillectomy was initially performed by general surgeons, but at the end of 19th century it became an ENT doctor's care, due to the best techniques of illumination that they knew. Important steps in the progress of the tonsillectomy were taken using mouth-gag and tongue-depressors, besides the positioning of patient with leaning and suspended head. This position was first described by Killian in 1920, but only adopted after improvements on anesthesia techniques ${ }^{2,3}$.

Even with a good use of Phisick's tonsilotome and similar instruments at the end of 19th century, another device started being attracted by the ENT doctors. Joseph Beck was the first one to describe the use of a device with cutting wire inside a rigid ring known as BeckMueller's ring. An instrument that also gained publicity in that period was Sluder's guillotine. At the beginning of 20th century, the use of forceps and scalpels resulted in less bleeding ${ }^{3}$.

From 1909, tonsillectomy surgery became a common and safe procedure, when Cohen adopted ligature of bleeding vessels to control perioperative hemorrhage. Sluder's tonsilotome had its first routinely uses in the United States in 1909, in Austria in 1910, and in Belgium in $1912^{3}$.

In Brazil, the first tonsillectomy was performed in 1920's by Schmidt Sarmento, a surgeon from Santa Casa de São Paulo ${ }^{3}$.
Therapeutical advance in medicine, especially with the use of antibiotics and improvement on work conditions on public health services and on group medicine also contributed for a reduction on tonsil removal surgery.

The chronic infection of tonsils and its systemic repercussions have been affecting human beings since far-off time. One of the most famous cases is the one of the first president of the United States, George Washington, who died in 1799 of peritonsillar abscess. The president died that night, December 14, $17999^{4}$.

At the beginning of 20th century, many authors recommended and performed partial tonsillectomy, but from the third decade of this century, the total tonsillectomy became preferential procedure.

In 1827 Philip Physick, from Philadelphia, announced an improvement in the method of handling with cotton wire. However this method caused 12 hours of pain and discomfort to patients. Physick tried another quicker method to perform tonsillectomy. He carried through research with old surgical instruments and found a device called uvulotome, which was originally created in the 16th century ${ }^{5}$.

Uvulotome was used to remove the uvula. An important aspect of the uvulotome was a circular opening where the uvula was introduced. Once placed, the uvula was cut off by a retractable blade. To apply the drawing of the uvulotome in the tonsillectomies, Physick made two modifications in 1828. First, he enlarged the diameter of the circular opening. Second, a piece of hemp wire soaked in oil was placed in the posterior part of the opening to supported tonsil and to obtain a clean cut. This new instrument was called tonsilotome, which was modified along the time ${ }^{6}$. 
William Fahnestock incorporated a small hook in order to hold tonsil. Even with an expressive speed increasing of the tonsillectomies, the tonsilotome did not prevent other ENT doctors developed new equipment and techniques to perform surgical procedure.

Gregg Dillinger used to believe that tonsilotome caused hemorrhage and then he developed a method called diathermy. Diathermy was the electric flow use in high frequency to raise tissue temperature.

From 1913, radiotherapy with x-ray in chronic or hypertrophic tonsillitis started to be recommended instead of surgery for some time, mainly in Europe ${ }^{6}$.

\section{Recommendations}

The recommendations are still a dynamic process; and, with a better knowledge on the implications of tonsil and adenoid disease, these recommendations have changed. Currently, the main recommendations are: obstructive hypertrophy during childhood, rebel recurrent infections to clinical treatment; peritonsillar abscess in recurrent tonsillitis \& neoplasm. Many new techniques other than cold steel tonsillectomy, now a days, cold steel dissection with (bipolar or monopolar) diathermy haemostasis, Bipolar ( forceps or scissors) diathermy, Monopolar diathermy, Coblation, Ultrasound tonsillectomy, Harmonic scalpel tonsillectomy, Laser tonsillectomy, Powered microdebrider are used in developed world.
Although considered rather dated by some, the cold steel technique for tonsillectomy has stood the test of time as an effective and safe operation.

\section{Dr. Kamrul Hassan Tarafder}

Professor, Department of OtolaryngologyHead \& Neck Surgery,

Bangabandhu Sheikh Mujib Medical University Shahbag, Dhaka, Bangladesh.

\section{References :}

1. Felisati D, Sperati G. Italian ORL Society Past and Present, The golden age of tonsillectomy, 2005;69 -73

2. Young J.R, Bennett J. History of Tonsillectomy. ENT News. 2004;13: 34-35.

3. Feldmann H., 200 year history of tonsillectomy. Images from the history of otorhinolaryngology, highlighted by instruments from the collection of the German Medical History Museum in Ingolstadt. Laryngorhinootologie. 1997;76 (12):751-60.

4. Lasmar A, Seligman J: História (e histórias) da Otologia no Brasil. Revinter. 2004.

5. Balbani APS. Personagens da História da Otorrinolaringologia. Arq. Int. Otorrinolaringol. 1998; 2(2): 54

6. Weir N. History of Medicine: Otorhinolaryngology. Postgrad. Med. J. 2000; 76: 65-69. 